The Geneva Papers on Risk and Insurance, 18 (No. 67, April 1993), 174-189

\title{
Electronic Communications in the Insurance Markets
}

\author{
by Douglas Shillito*
}

\section{Introduction}

Electronic communications in the insurance markets is a major strategic business issue. In looking at progress so far across the world, the tendency has been for each national insurance market to go about its own development in its own way, although there are now signs that some of the European Continental countries have learnt from the earlier experiences of the U.S.A. and the U.K.

There is a different state of development in each country, and whilst national characteristics of markets will inevitably be reflected in the speed and diversity of electronic communications, it is useful at this stage to look at some of the strategic issues which affect all national markets, and increasingly are becoming important for global players.

\subsection{Distribution and control}

Electronic communications are at the very heart of distribution strategy and channel management. Information technology itself has provided wider options to insurers beyond the traditional methods of distribution. Worldwide trends across markets indicate general liberalisation with newer, major, players coming in. The influence of these newer players, together with the diversity of distribution channels, some of which would not be contemplated without the availability of information technology, is leading to an increasingly competitive marketplace that is undergoing considerable structural change.

In the light of all these changes, which will continue to escalate, most markets are, or will be, experiencing human resource problems, such as the demographic downturn in school leavers, and the changing demands for insurance and pensions as control moves from the State to the private sector.

\subsection{An opportunity for collaboration and co-operation}

The development of electronic communications is in fact the glue that will enable the jigsaw to be put together. There is an opportunity to learn from past mistakes and lay down the foundation of a blue-print for success in the future both at national and international level. Most domestic markets and international initiatives so far have still to be

* Managing Director, Shillito Market Intelligence Ltd., U.K. Worldwide Trend Survey sponsored by the Geneva Association. 
clearly understood and supported by top management. Perhaps the biggest issue is for market players to identify which aspects of electronic communications should be co-ordinated at industry and international level without diluting their own competitive position.

Most co-operation across markets so far has been at the technical level in establishing standard insurance related data messages. This has been slow and very much on a piecemeal basis, but is now becoming very much a worldwide issue. The development of message standards, however, is only one aspect to be considered. The development of standard "interfaces" between systems are proliferating, whether internally developed or available from a third party source. In some markets, the confusion in this area has meant that both insurers and intermediaries have delayed their investment in electronic communications since it has proved difficult to justify the benefits of the investment to senior management. The international relevance of "interface" is becoming more important as application software vendors sell their systems across country and continental boundaries with multilingual and multi-currency facilities.

\subsection{Who controls electronic communications?}

Insurance markets have varied in their approach to the control of electronic communication development. For example, in the U.K., the retail market has allowed a number of network carriers and network services companies to control the pace of development and broking systems houses have been introducing their own "interface" systems. On the other hand, Belgium's ASSURNET and the European initiative, RINET, are being developed through an industry organisation which is composed of market players which decides the network carrier, and the nature and speed of the development of services and prices. Another related issue is whether a market should have a single network carrier or a choice of more than one.

In summary, the implications of electronic communications need to be understood by senior management in order that investment can be made to support company and industry strategies. There is no doubt that the level of co-operation and collaboration at precompetitive level is now increasing, and that some domestic markets are performing far better at solving the human and technical issues surrounding this vital subject than others.

Commitment is required by insurers, intermediaries, systems suppliers and network carriers to ensure that both domestic and global markets have an opportunity to establish and maintain an efficient level playing field in electronic communications.

In many respects, the insurance markets are at a crossroads. Do they encourage awareness and co-ordination of electronic communications or is there a preference for leaving market forces to dictate the speed and direction of electronic communications development?

This worldwide survey of senior management aimed to establish, in broad terms, the current and future progress of electronic communications in the insurance markets, and to identify areas for co-operation, the desire, and the means.

\section{The objectives of the survey}

The objectives of the Trend Survey were to identify in broad terms the major present and potential future issues surrounding the use of electronic communications in the insurance markets domestically and internationally. 
The questionnaire was divided into five sections:

1. Present and future use of electronic communications.

2. Benefits and problems. Benefits achieved and anticipated and problems experienced and anticipated.

3. The human interface, identifying areas for co-operation and awareness/training.

4. Applications, in operation and to be introduced within the next three years.

5. Possible areas for action. Possible areas for industry action broken down into "vital", "desirable", and "not in favour".

\subsection{Respondents}

There were thirty-five respondents in the following categories:

$\begin{array}{lr}\text { Composites } & 19 \\ \text { Reinsurers } & 5 \\ \text { Life Offices } & 5 \\ \text { General Insurers } & 5 \\ \text { International Brokers } & 1\end{array}$

Their head office is situated in the following countries:

$\begin{array}{lr}\text { U. K. } & 14 \\ \text { Italy } & 3 \\ \text { Sweden } & 3 \\ \text { Australia } & 2 \\ \text { Germany } & 2 \\ \text { Spain } & 2 \\ \text { U. S. A. } & 2\end{array}$

and one from each of the following: Belgium, Canada, France, Greece, Netherlands, Portugal and South Africa.

\section{Summary of results}

\subsection{Present and future use}

Domestically, two-thirds of respondents were electronically communicated to their branch offices on a two way communication basis using private networks. $25 \%$ of the respondents were using industry/public networks

$50 \%$ were linked to independent brokers by public/industry networks - twice as many as private network users. A third had electronic links to cedants and/or reinsurers through industry/public networks, again twice as many as private networks. A third of the respondents had private electronic links to direct salesman - half as many were using industry/ public networks. $50 \%$ were linked to tied agents using private networks, one-third also using industry/public networks. Major increases in connectivity within the next three years will be with independent brokers and reinsurers/cedants. $20 \%$ of respondents had electronic links with clients and a steady growth is anticipated - industry/public networks had slightly more users than private networks in this regard. 
On the international front, of the seven companies responding to this question none were at present linked to foreign intermediaries. Only three respondents had electronic links to their branches, using industry/public networks with two of them also using private networks. Three respondents were linked to reinsurers/cedants using industry/public networks. Two had international links to clients using both private and public networks.

\section{PRESENT AND FUTURE USE}

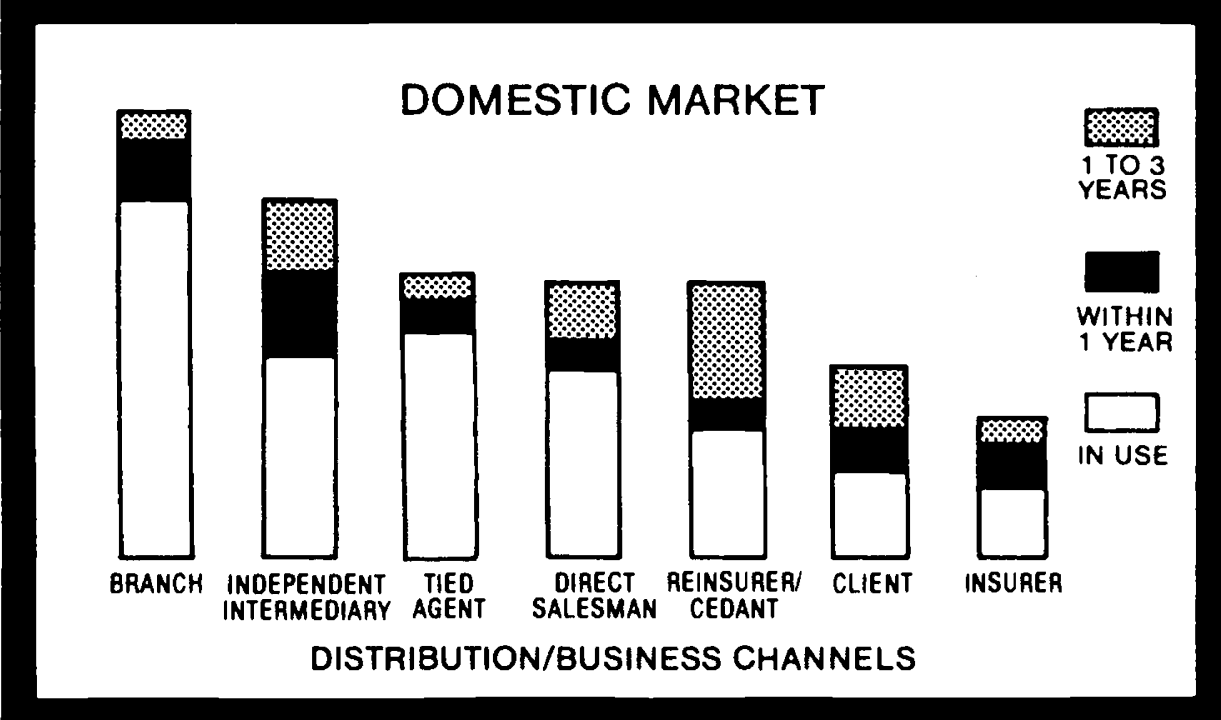

\section{Benefits and problems}

The results of the survey indicate close matching between benefits achieved and/or perceived in the area of staff savings, better relationships with distributors, saving on overheads, better management controls, control of costs, and delegation of responsibility, although most of these were in the medium range of response.

Interestingly, benefits achieved were higher than perceived for improved service levels, reduced duplication, competitive edge, and single data input whereas there is a much higher perception of benefits for wider distribution options and industry data standards as a platform. Some of the benefits listed are clearly linked such as reduction in duplication and saving in overheads but it is also clear that some benefits will take longer to be achieved than others and that, particularly for the independent sector, the establishment of industry data standards will be a key element.

By comparing problems experienced and perceived, and by asking respondents whether they thought they were easy or difficult to overcome, again there is sometimes quite a large gap. The response to the problems question was lower than the earlier one on 
benefits but clearly some problems will reduce and in some cases disappear over a period of time - for example, security, availability, interface to internal systems, difficult to use, speed, and poor connectivity score very low as "difficult to overcome" issues. However, interfacing at present is causing some difficulties to some respondents, particularly to external systems. Also short term is critical mass as far as perception is concerned and there are still a fair number of pessimists amongst "present experience". Interestingly, return on investment still looks like a difficult nut to crack for a high proportion of respondees to this question and industry restructuring it also considered to be troublesome.

Looking at lack of control by the industry nationally, costs and developments are perceived to be more stubborn issues at present than in the future.

On the international front, systems interfacing is perceived to be a long term problem whilst those involved in existing development feel it will be difficult to overcome if there is lack of industry control.

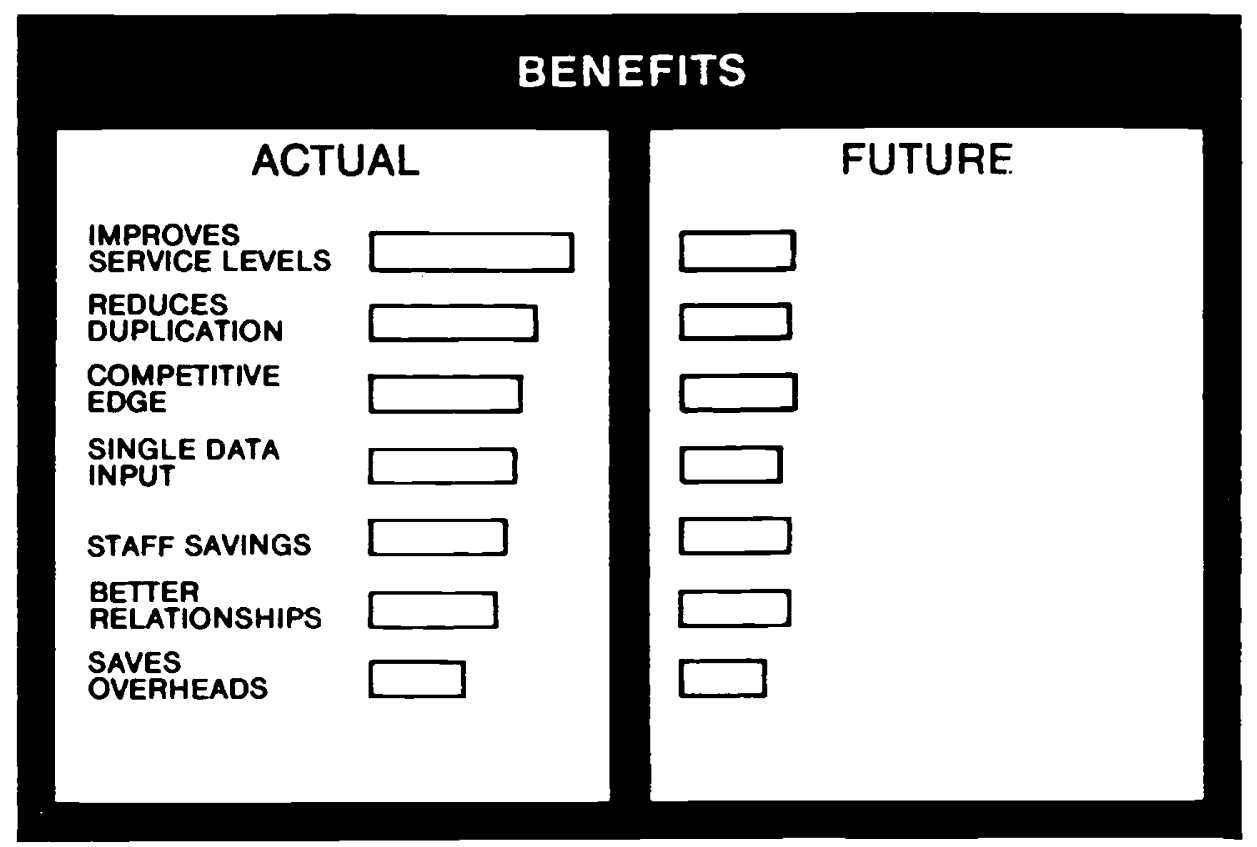




\section{BENEFITS}

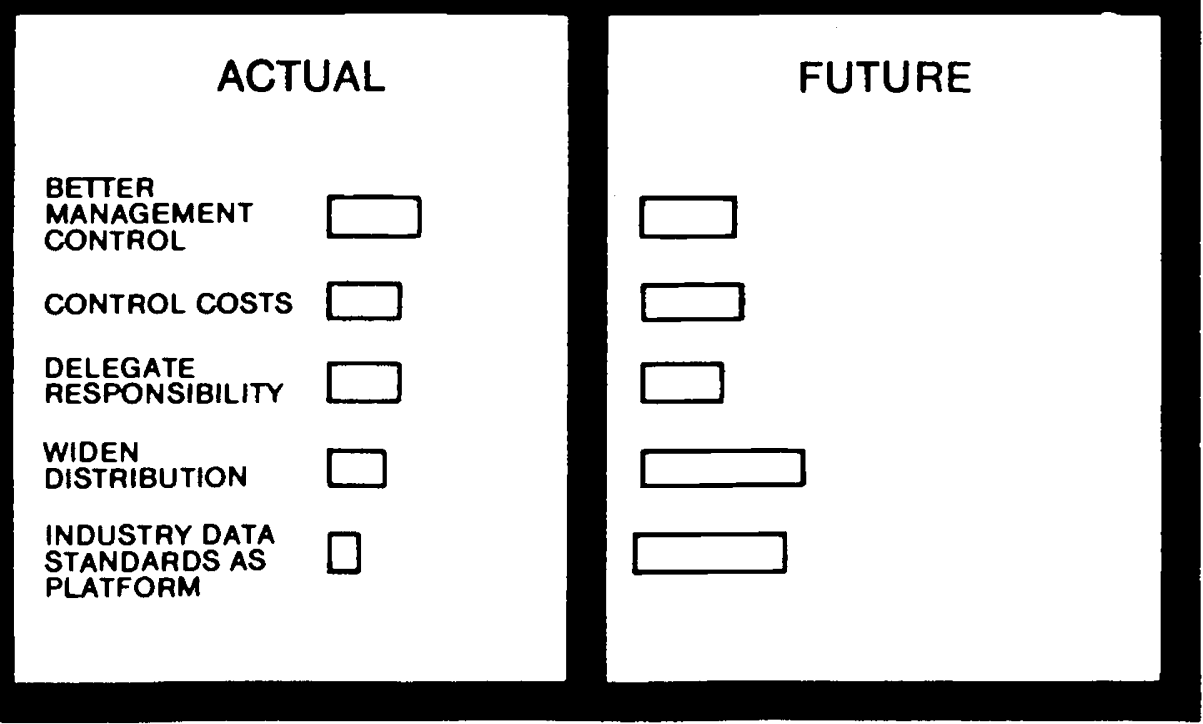

\section{PROBLEMS}

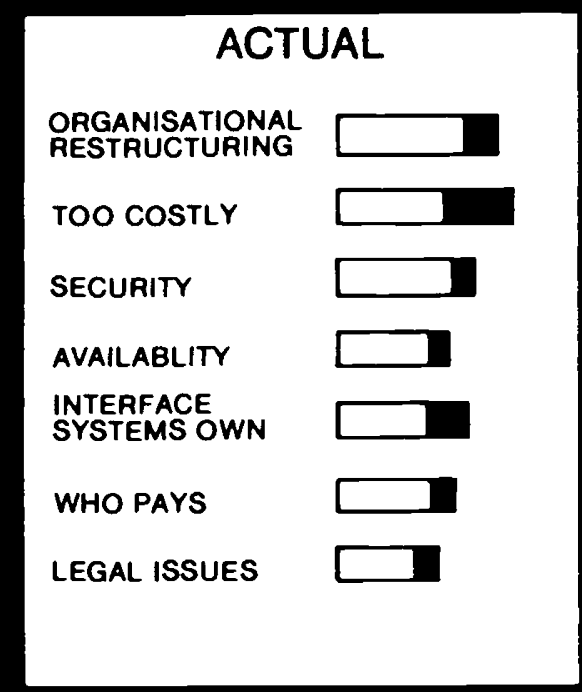

FUTURE
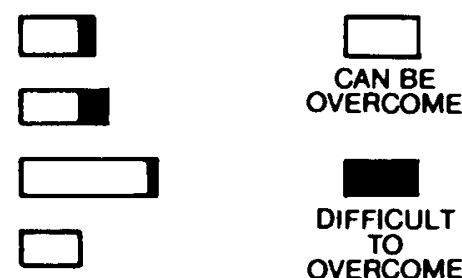

TO

OVERCOME 


\section{PROBLEMS}

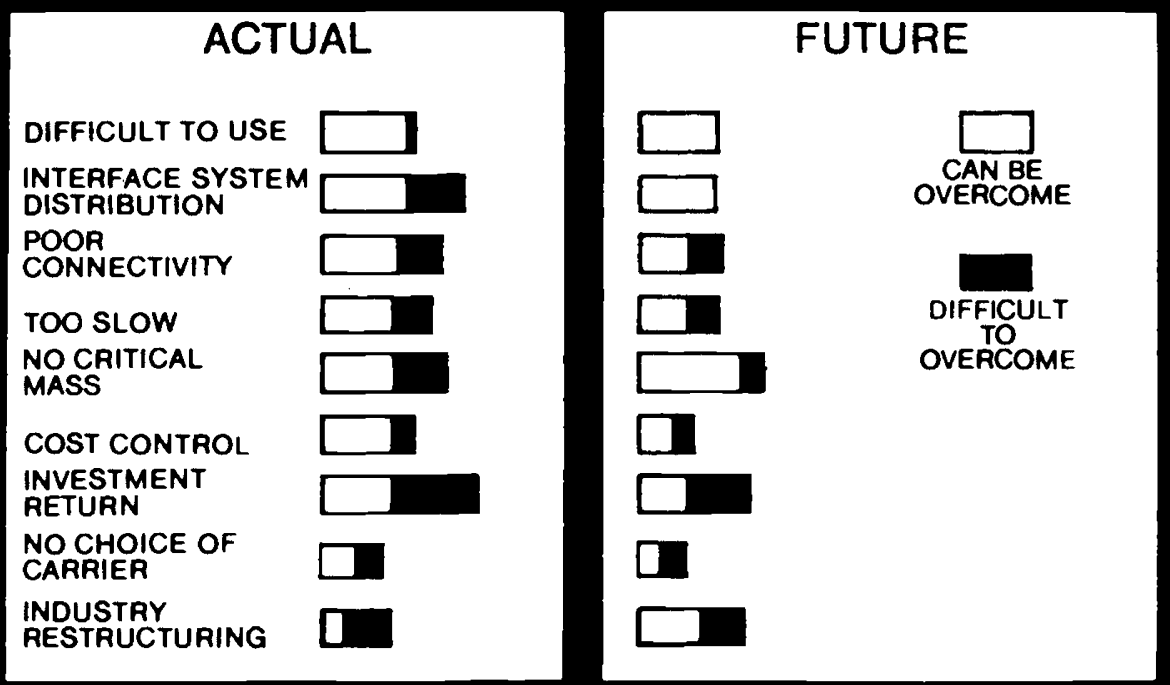

\section{LACK OF CONTROL BY INDUSTRY NATIONALLY}

ACTUAL

SYSTEMS

INTERFACING

TRAINING

CHOICE OF

CARRIER

$\cos T$

DEVELOPMENT
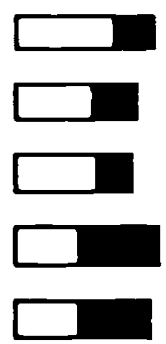

FUTURE

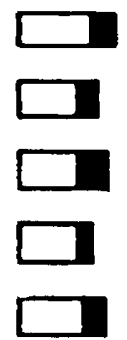

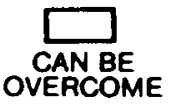

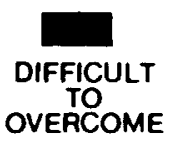




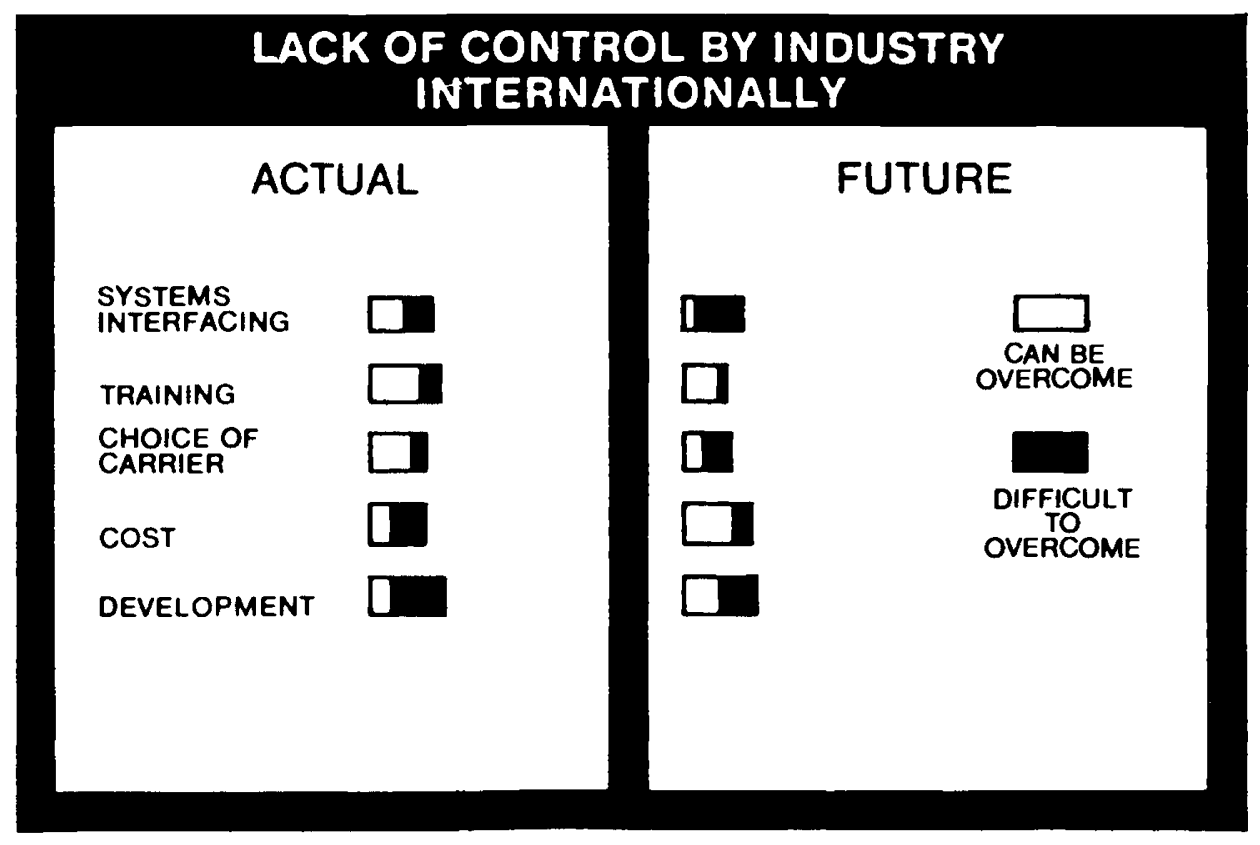

\section{THE HUMAN INTERFACE}

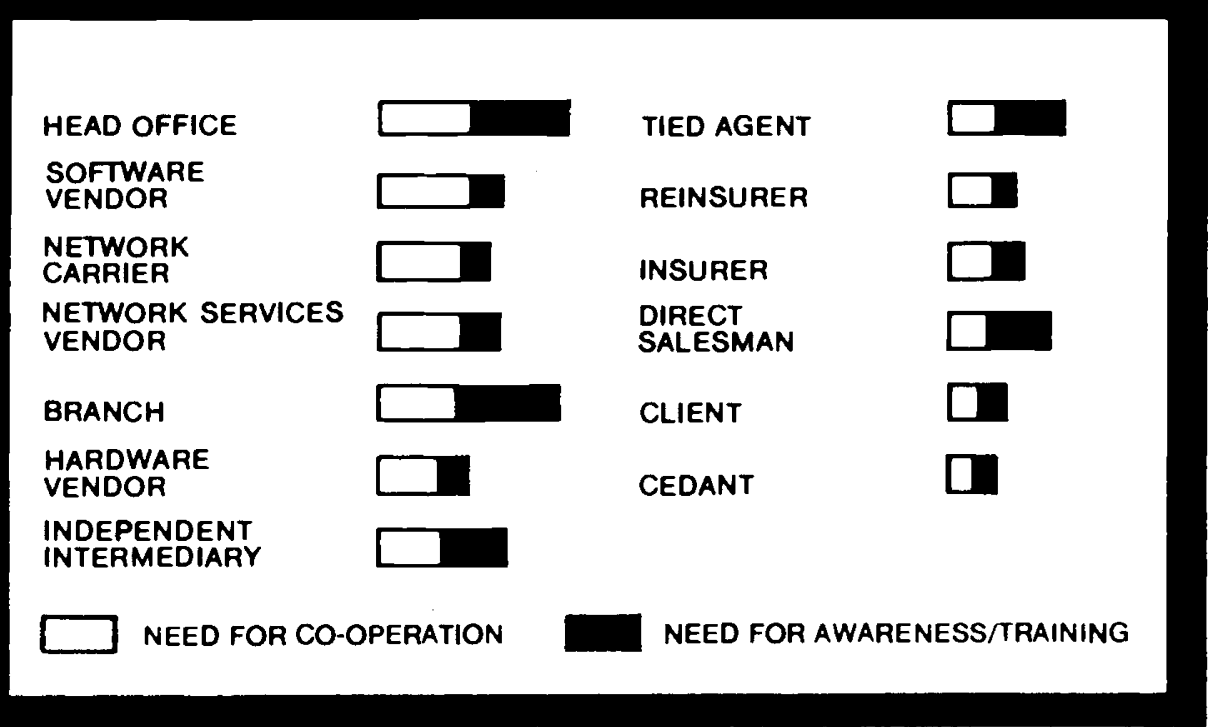




\section{The human interface}

As expected, head office and branch scored highest across both questions in the need for co-operation and awareness/training. There is also very high scoring for co-operation from software vendors, network carriers, and network services vendors with hardware vendors not far behind. The survey highlighted that half the respondents saw awareness/ training issues relating to direct salesmen and tied agents where the same number saw an equal need for co-operation and awareness/training from and for the independent intermediary.

\section{Applications}

Because the survey was across all classes of business, the trends indicated in the answers to this section should be treated very broadly. The aim was to indicate the major transactions and information services and highlight the present penetration, and growth over the next twelve months and one to three years. Many of the existing connections will be between head office and branch as opposed to delegation to distribution channels. Applications scoring lower in terms of present penetration were risk management, investment, product and company dispersal of information, and transmission of software programs. In terms of access to services, expect a considerable growth in financial planning, modelling, claims analysis, and, to a lesser degree, underwriting.

On-line information enquiries will increasingly be available as will access to market information services.

\section{APPLICATIONS}

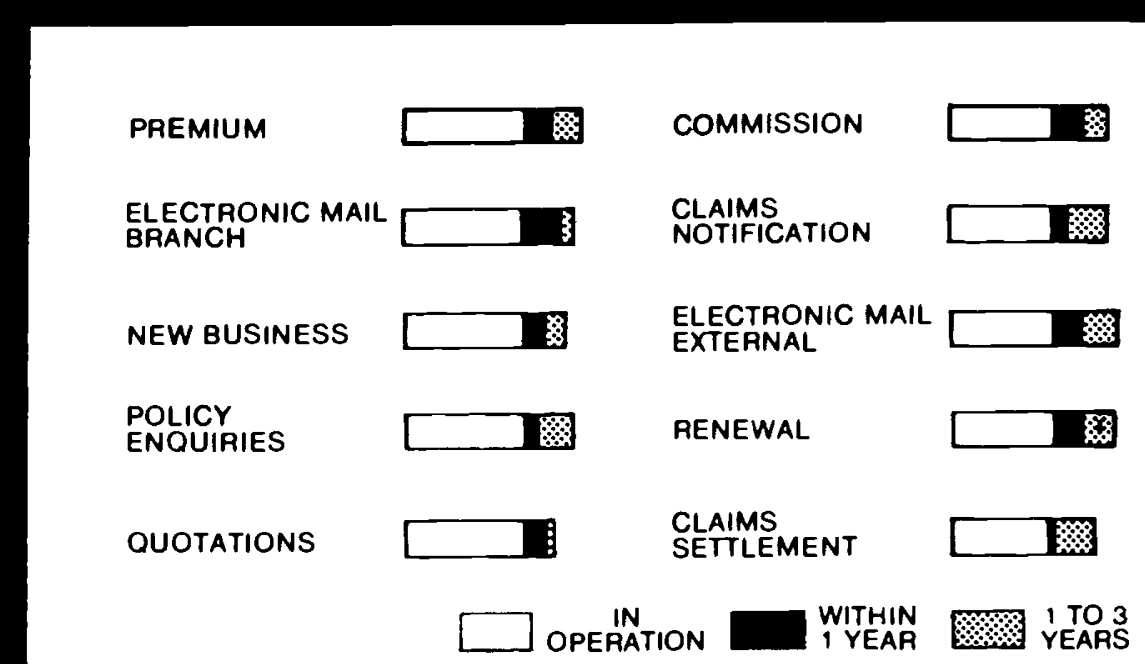




\section{APPLICATIONS}

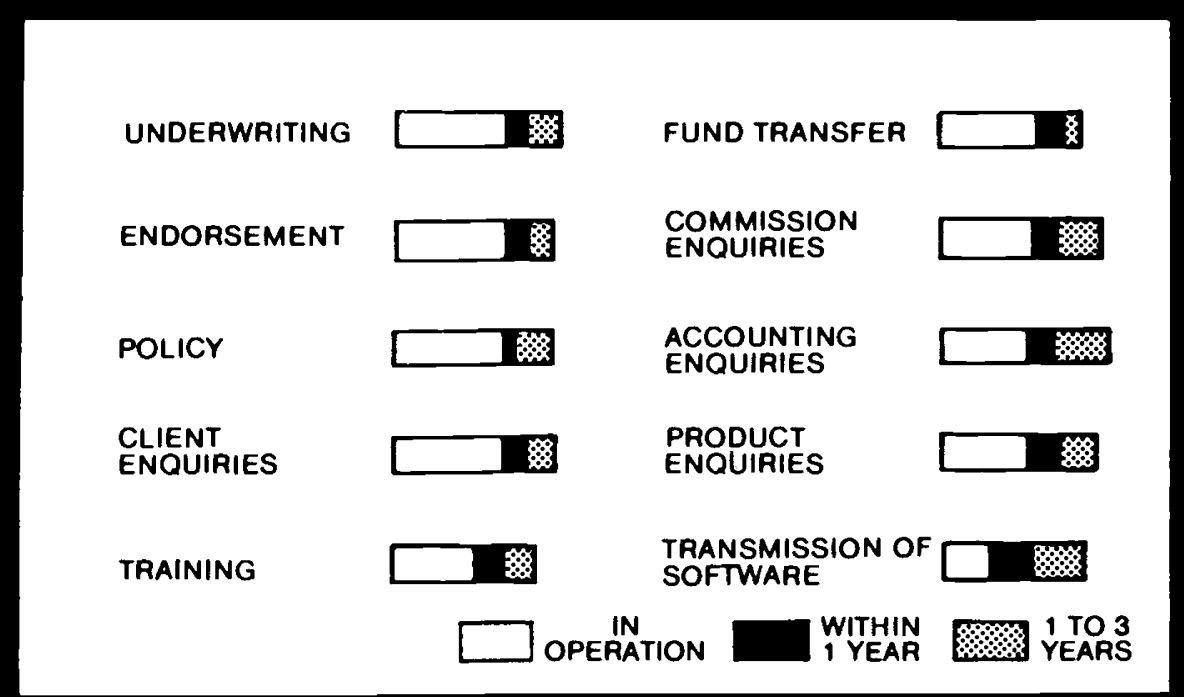

\section{APPLICATIONS}

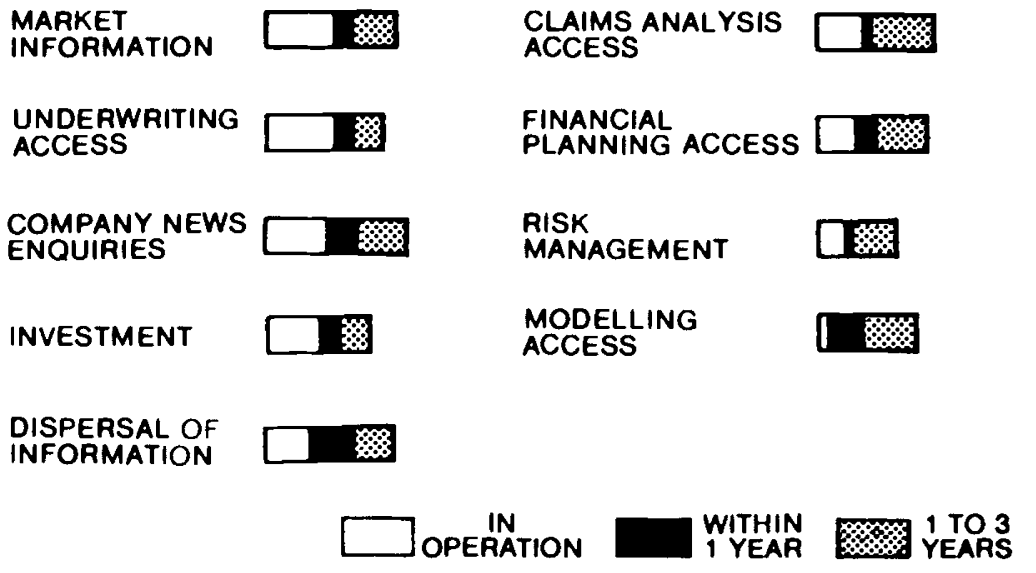




\section{Possible areas for action}

$50 \%$ of respondents felt greater awareness of relevant non-insurance experiences was "desirable". Nearly one-third felt it was "vital" to be kept up to date with other national market developments and experiences whilst two-thirds thought it was "desirable".

The development of common external systems interfacing was a key issue $-50 \%$ of the respondents felt it was "vital" whilst virtually all the others put it in the "desirable" category. Another key issue was speedier more strategic approach to insurance data standards with just over $50 \%$ putting it in the "vital" category with the remainder regarding it as "desirable".

In response to the question regarding the potential establishment of an international co-ordination organisation, one-third of respondents felt it was "vital" to oversee international insurance communications development with $50 \%$ regarding it as "desirable" six respondents were not in favour. Around $50 \%$ to $60 \%$ of respondents felt it would be useful for such an organisation to liaise with existing or potential network carriers, network services vendors, hardware vendors, and international insurance software vendors. Scoring highest in the "vital" category was liaison with network carriers and network services vendors.

Two-thirds of respondents felt that the creation of a market electronic communications platform domestically was "vital" or "desirable", in equal proportions. Internationally, a similar number regarded a platform as being "vital" or "desirable" with only six in the former category. Two-thirds of respondents were not in favour of a laissez faire market approach to electronic communications domestically or internationally.

Two-thirds felt that it would be "desirable" to have electronic communications coordination internationally as part of a wider awareness initiative involving emerging technologies such as expert systems and document image processing for example. Only seven respondents were against this idea.

In terms of promoting wider awareness of the issues surrounding electronic communications, occasional papers were top of the list with $80 \%$ regarding them as "desirable". Seminar/workshops for senior management and technical management followed closely behind in the same category. The rest of the views were split virtually equally between "vital" and "not in favour".

Turning finally to the hot topic of who would fund/sponsor the acceleration of insurance electronic data standards, $40 \%$ of respondents felt that insurers and reinsurers had a "vital" role, followed by intermediaries. Again, in the "desirable" category, insurers and reinsurers topped the list with about half the respondents but all the remaining categories were not far behind. However, there was quite a strong vote by around $30 \%$ of the respondents for hardware and software vendors not to be involved. 


\section{POSSIBLE AREAS FOR ACTION}

\section{A NEED FOR GREATER}

AWARENESS OF:-

other insurance market awareness development/ experience

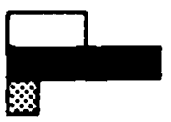

non-insurance experiences, that are relevant

ก

$\%$

$\square$ VITAL DOESIRABLE NOT IN

\section{POSSIBLE AREAS FOR ACTION}

THE DEVELOPMENT OF:-

common external systems

interface development

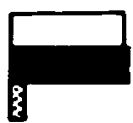

speedier more strategic, approach to insurance data standards

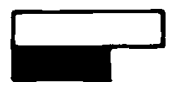

VITAL 


\section{THE ESTABLISHMENT OF AN INTERNATIONAL CO-ORDINATION ORGANISATION}

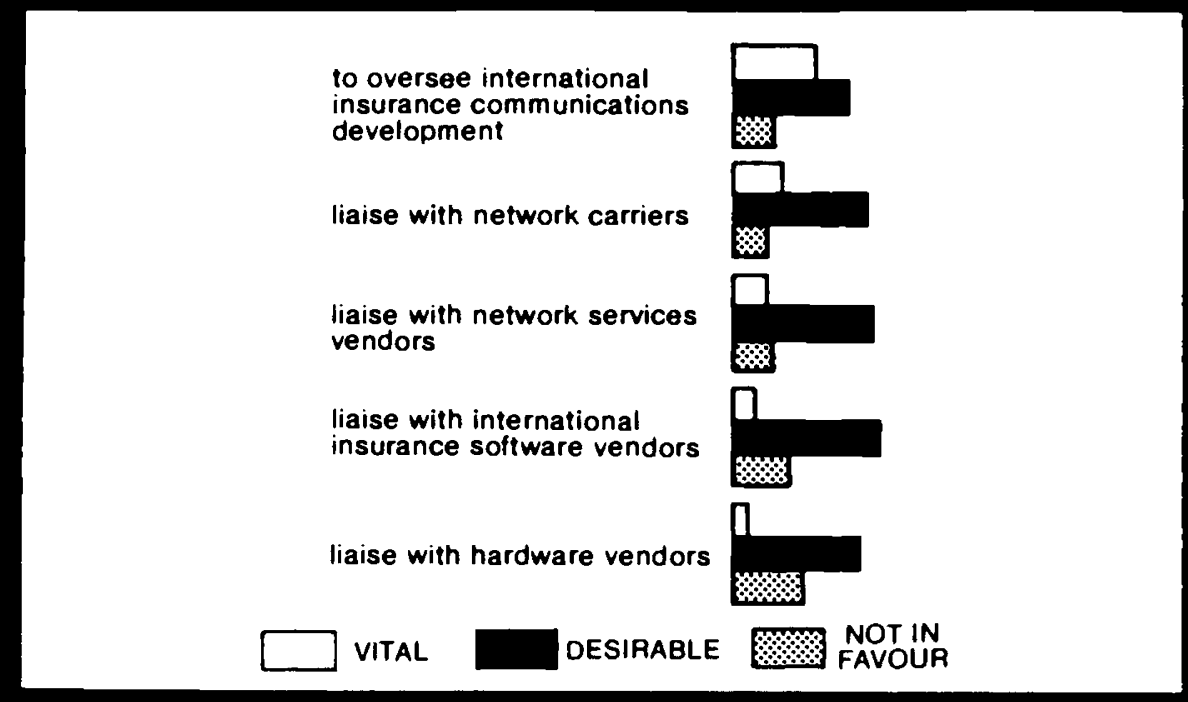

\section{MARKET ENVIRONMENT}

THE CREATION OF A MARKET ELECTRONIC

COMMUNICATIONS PLATFORM

$\%$

internationally

A "LAISSEZ FAIRE" MARKET APPROACH
$\%$
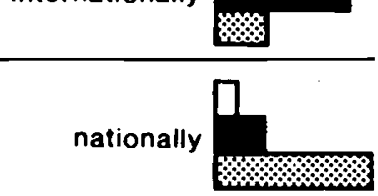

internationally

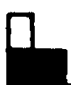

NOT IN

FAVOUR 


\section{POSSIBLE AREAS FOR ACTION}

ELECTRONIC

COMMUNICATIONS

CO-ORDINATION

INTERNATIONALLY AS PART OF

A WIDER AWARENESS

INITIATIVE INVOLVING

EMERGING TECHNOLOGIES

SUCH AS EXPERT SYSTEMS,

DOCUMENT IMAGE

PROCESSING, ETC.

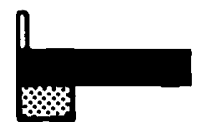

$\square$ VITAL

DESIRABLE NOT IN

\section{POSSIBLE AREAS FOR ACTION}

WIDER AWARENESS

PROMOTED BY:-

seminars/workshops for

senior management

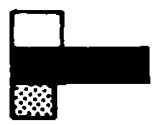

technical management

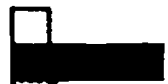

\%

occasional papers

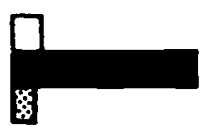

VITAL

DESIRABLE NOTIN 


\section{DATA STANDARDS SPONSORSHIP}

\section{ELECTRONIC COMMUNICATION INSURANCE DATA STANDARDS ACCELERATED BY FUNDING/ SPONSORSHIP FROM:-}

insurers

reinsurers

intermediaries

hardware vendors
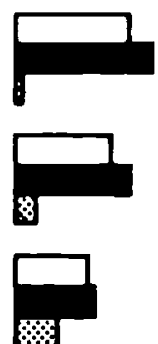

software vendors

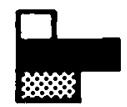

network carriers

network services \&

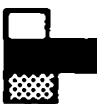

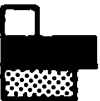

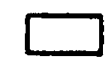

VITAL

\section{Summary}

The overall view coming out of the survey, and confirmed in informal discussions after presentation of the results at seminars in London and Venice, is that a "laissez faire" approach to electronic communications development in the insurance markets both domestically and internationally is firmly rejected. Respondents clearly see the need for far more co-operation between markets than has been established at the present time, and there was a surprisingly high response by senior management to the need to be aware of relevant experience outside the insurance industry.

In answering the benefits and problems section, it is significant that benefits such as widening distribution options and insurance data standards as a platform has still to be achieved. There is still a major concern from senior management about the return on investment in electronic communications, and industry restructuring is a long term problem to be solved. 
The creation of an international co-ordination organisation to oversee international insurance electronic communications development got a high rating and could well be coupled with providing a wider awareness of the closely linked emerging technologies such as expert systems and document image processing. There is an overwhelming plea for the development of insurance data standards to be escalated, and external systems interface to be co-ordinated.

The survey indicates a high desire for wider awareness for both senior and technical management through seminars/workshops and occasional papers.

The survey concentrated on identifying areas of similarity across markets even though distribution channels vary. It is interesting to note that domestic market co-operation on electronic communications is not restricted to just those markets where there is a strong independent intermediary sector. 